\title{
AiMT
}

Advances in Military Technology

Vol. 13, No. 2 (2018), pp. 265-275

ISSN 1802-2308, eISSN 2533-4123

DOI 10.3849/aimt.01255

\section{Design and Static Load Analysis Comparing Steel, Grey Cast Iron and Titanium Alloy as Materials for Breech Hinged Lugs in Recoil Weapons}

\author{
E. Chaturvedi* and R. K. Dwivedi \\ Maulana Azad National Institute of Technology, Bhopal, India \\ The manuscript was received on 6 May 2018 and was accepted \\ after revision for publication on 20 November 2018.
}

\begin{abstract}
:
This design innovation work is related to design validation of short recoil weapons mechanism's critical components in context of upper receivers. It explains a new mechanism for locking and unlocking of bolt with the breech and subsequent advantageous design changes in the bolt's construction. This design intends to build a new platform for a short recoil weapon chambered in 5.56 $\times 45$ NATO ammunition which promises competency with its existing counter parts of the same domain, but exhibiting exceptionally improved reliability due to elimination of interdependence of reciprocating cycles of barrel and bolt assemblies. This work involves the design of the whole functioning system using Solidworks 2015 version and a static structural analysis to compare and choose the most suitable material among commonly used ones: steel AISI 4340, grey cast iron and titanium alloy Ti-6Al-4V, for locking lugs, being critical pair of components, using ANSYS 14.5. Results showed that titanium alloy was the most suitable material for the strength purpose. It is to be noted that this system may not only be utilized for assault rifles, but also for sub-machine guns, machine gun variants and even in handguns.
\end{abstract}

\section{Keywords:}

short recoil weapons, wedge cam lugs, breech, barrel assembly, cam frame

\section{Introduction}

Compared to the most frequently used gas-operated action, the short recoil system has a universal advantage against the fouling of internal parts due to carbon deposits in the long-term use. The problem of fouling can be tackled very well by recoil or inertia

\footnotetext{
* Corresponding author: Department of mechanical engineering, Maulana Azad National Institute of Technology, Bhopal, India. Phone: +91-9981221709, E-mail: ekanshchat96@ gmail.com
} 
operated weapons, as gas orifice is not required in them. But the major problem with currently used short recoil systems is their complicated assembly construction and mostly the interdependence of barrel's repositioning time and bolt's cycle time [1], which means that during the forward stroke of bolt, the barrel assembly must have reached the original position before the bolt shuts down the cartridge into the battery. If the system fails to do so, the gun jams. It is this second stated problem that this invention intends to tackle. In concern to this invention, efforts have been made to transform the breech locking system to a much simplified form. Hence, the so called intricacies in short recoil action can be resolved, thus making the weapon much more user-friendly, reliable, and adaptable to adverse conditions.

Hence the advantages offered by this mechanical platform are as follows:

1. Fewer moving parts as there is no providence for a rotating or tilting bolt head.

2. No multi-lug system (as that in AR-15 platform counterparts), thus making the manufacturing process of barrel and bolt easier and cheaper.

3. The bolt is a single piece body with no intermediate moving parts (i.e. no bolt carrier group / operating rod) thus it gives an improved reliability, and a lightweight structure.

4. Shorter size of bolt and lighter structure does not require a very stiff spring, and even if such stiff springs are used along with the light structured bolt, pretty high rates of fire can be obtained, which is an ideal requirement for machine guns.

5. No orifice in the barrel for gas transfer, thus there is no risk of fouling of the internals (gas tube, operating rod or bolt itself).

6. Lower reciprocating mass (bolt) helps to reduce the $3^{\text {rd }}$ element of recoil.

This operating mechanism is better than the rotating bolt mechanism because it eliminates the dependence of proper bolt locking on the time taken by the barrel to gain its original position. It was an utmost requirement in that mechanism that the barrel should not snap forward before the bolt does not complete its cycle, i.e. until and unless the bolt does not sit into the breech. This dependence made the mechanism unreliable and malfunctions were very frequent.

\section{Methodology and Analysis}

\subsection{Functioning Mechanism}

It is to be mentioned that since the bolt is a single-piece body reciprocating on slides / frame and also supported by the main spring guide rod, it is physically impossible for it to rotate or tilt.

As far as the working of mechanism and achievement of proper locking with breech is concerned, the following steps along with the pictures may be helpful:

1. Initially, the bolt resides in the breech with the cartridge in (cartridge not shown here) and the lugs are tilted inwards about the hinge shown in Fig. 1. When the firing pin hits the primer, the generated pressure tends to push the bolt back in the same way it forces the bullet out of the muzzle. But the lugs in the inward tilted position resist the bolt from travelling rearward. Since the barrel is not fixed, it recoils back (as in the case of every recoil-operated weapon) and while it does so, the lugs hinged to the same barrel cam along the wedge cam frame, as shown in Fig. 1. 
2. Once the lugs open, the bolt is free to reciprocate backwards under the reduced pressure thus extracting and sejecting the spent cartridge (Fig. 2). Simultaneously, the compressed barrel recoil springs bring the barrel-lug assembly back to its original position; i.e. the barrel snaps forward and the lugs move outward under their own spring's action (Fig. 3). The barrel's maximum recoil travel is constrained by high stiffness of recoil springs which compress to their maximum limit in such a way that adjacent coils rest upon each other. However, designs may utilise fixed protrusions built in the trunnion to stop the barrel from travelling past a certain limit. This maximum limit, in this case for demonstration purpose, is kept at $14.24 \mathrm{~mm}$; which however could be varied as per design constraints, which includes length and hence the weight of barrel etc. to ensure sufficiently reduced pressure for proper extraction of cartridge. The geometry of lugs would correspondingly undergo change in shape and size as well and the strength analysis would be required for all such cases.

3. Now, under the mainspring's compression, when the bolt would travel forward, striping new cartridge from the magazine, the bolt head would push the lugs out of their way, while entering into the breech (Fig. 4). And once the bolt head's rearmost part surpasses the foremost point on lugs (Fig. 5), the lugs will fall back into the locked position, thus completing the cycle (Fig. 6). This mechanism has the biggest advantage over the mechanisms used by Johnson [2], Browning [3] and Fedorov [4], as it eliminates the dependence of the barrel's repositioning time and the bolt's cycle time (as mentioned previously). It does not matter whether the barrel has returned to its original position or not, the striking bolt would however ensure that the bolt gets locked before the hammer strikes the firing pin.

\subsection{Strength Analysis}

Locking lugs [5] are critical components in any weapon assembly. They should be dimensionally right so that they can bear the high magnitude fatigue loads imparted due to very high pressures generated by the propellant combustion, without any failure. This hence validates the necessity of conducting this finite element simulation analysis $[6,7]$.

The finite element simulation [8-11] was conducted with fine-sized mesh and rest being default meshing settings in the following steps:

1. Fig. 7 shows the body of lug hinged to a cylindrical pin, which indeed would be hinged to the breech and of the barrel, under the fixed support at the circular faces of pin. This situation attempts to mimic the situation just before the moment of beginning of recoil of the barrel. It is that moment at which maximum acceleration will be attained. Material chosen for both was AISI 4340 steel in case 1 , grey cast iron for case 2 and titanium alloy Ti-6Al-4V in case 3 . The mechanical properties of these materials are shown in Tabs 1, 2 and 3 respectively [12].

2. Fig. 8 shows another fixed support at the rear fillet edge of the lug, mimicking the support from the cam surface of the wedge cam just at the moment when barrel begins to recoil.

3. Fig. 9 shows the calculated force imparted on one lug. Since there are two lugs in the proposed mechanism, the total maximum force generated divided by 2 gives the force imparted on one lug. The total maximum force is calculated by 
multiplying the bolt face area (area of the cartridge's rear circular face) with the maximum generated pressure in the barrel, shown in Fig. 10 [13]. The figure depicts that the pressure generated acts equally in all the directions and pushes the bullet from the front end of the muzzle. As well as it imparts recoil force to the bolt and/or barrel assembly. Indeed, the problem is much more complex, but for simplified visualisation, the maximum pressure value has directly been considered. Therefore, total maximum force $F$ is given as:

$$
F=p A,
$$

where $p$ and $A$ denote the values of pressure and area over which the pressure is acting.

The maximum pressure generated by $5.56 \times 45$ ammunition is $397.138 \mathrm{MPa}$, which is equal to $57600 \mathrm{psi}$ [13]. The area $A$, in this case, would be that of the rear end of the ammunition shell having diameter equal to $9.6 \mathrm{~mm}$.

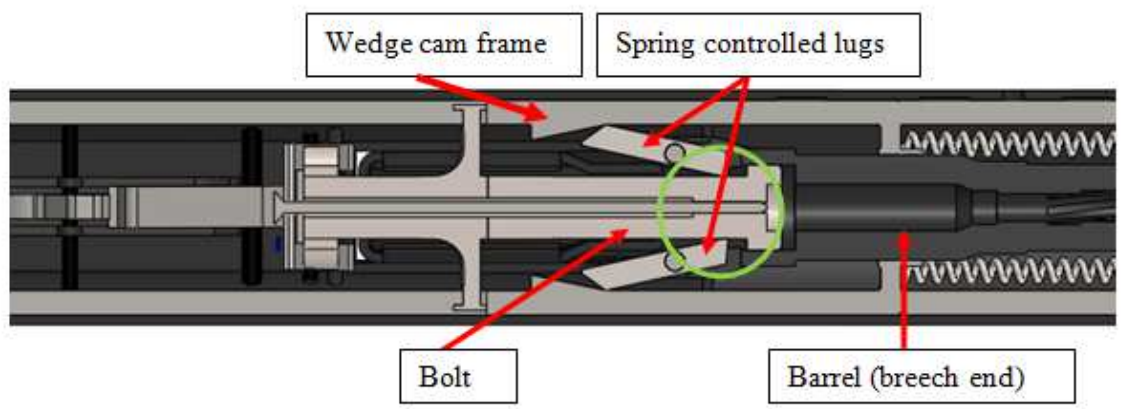

Fig. 1 Components in the mechanism

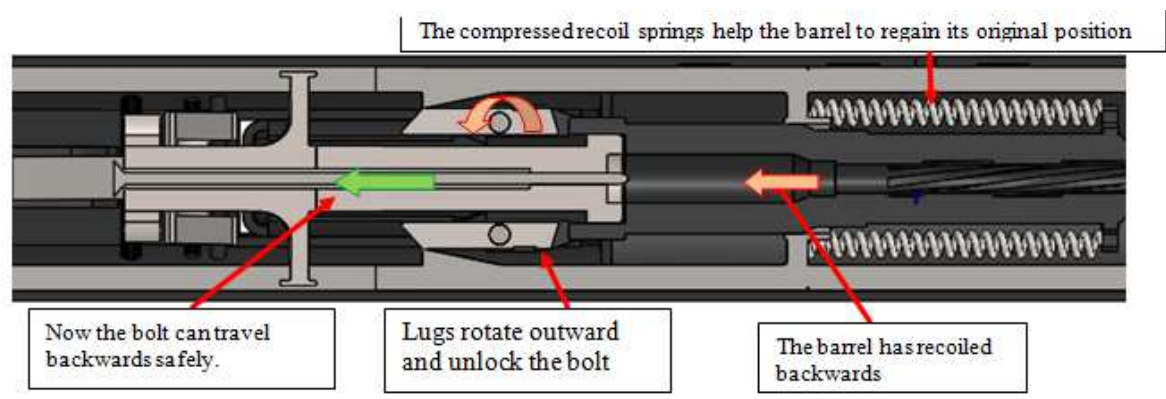

Fig. 2 Behaviour of mechanism as recoil begins

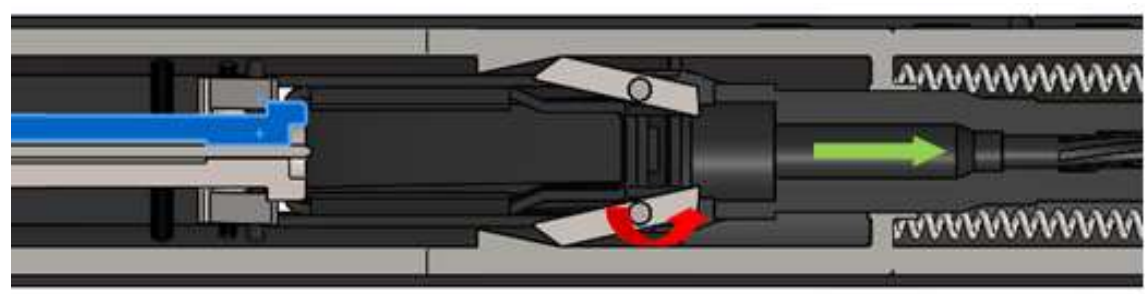

Fig. 3 Barrel completes recoil cycle 


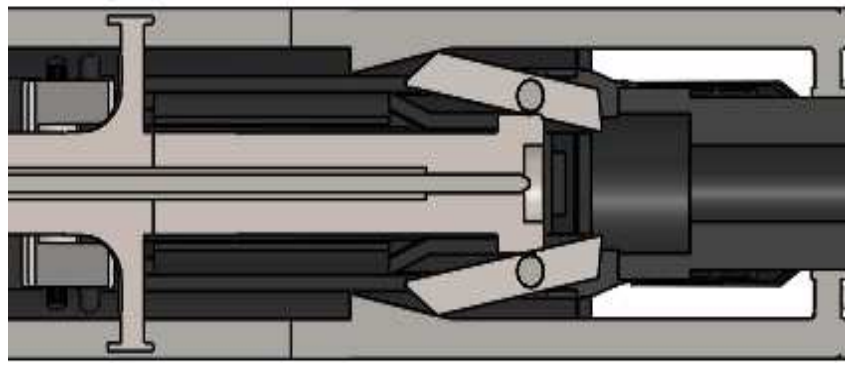

Fig. 4 Bolt begins to strike into breech

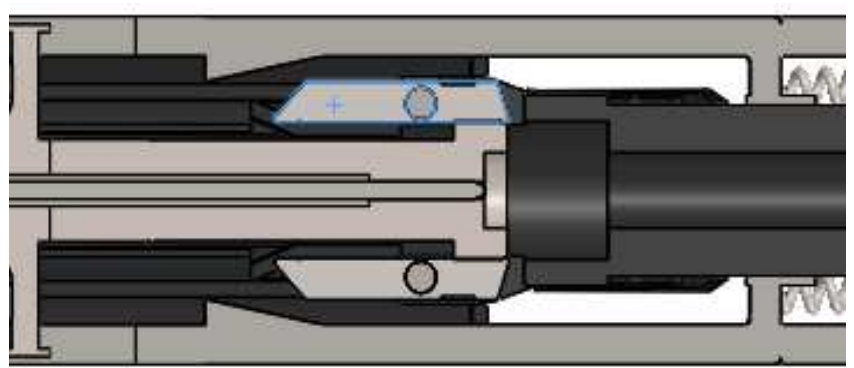

Fig. 5 Lugs open up as bolt head crosses them

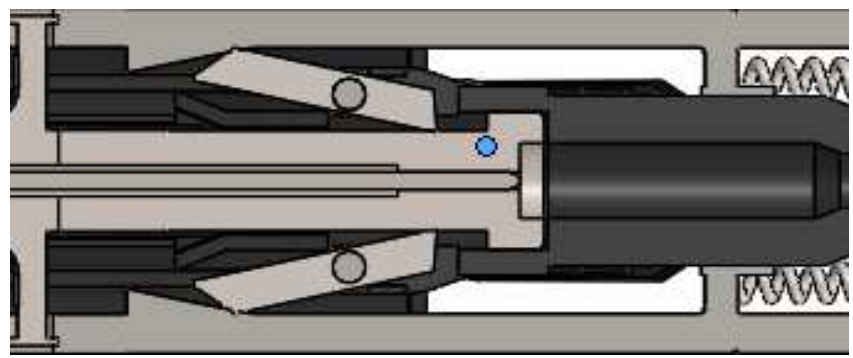

Fig. 6 Bolt is again in battery

Tab. 1 AISI 4340 properties

\begin{tabular}{|l|c|}
\hline Tensile strength & $745 \mathrm{MPa}$ \\
\hline Yield strength & $470 \mathrm{MPa}$ \\
\hline Bulk modulus (typical for steel) & $140 \mathrm{GPa}$ \\
\hline Shear modulus (typical for steel) & $80 \mathrm{GPa}$ \\
\hline Elastic modulus & $190-210 \mathrm{GPa}$ \\
\hline Poisson's ratio & $0.27-0.30$ \\
\hline Elongation at break & $22 \%$ \\
\hline Reduction of area & $50 \%$ \\
\hline Hardness, Brinell & 217 \\
\hline
\end{tabular}


Tab. 2 Grey cast iron properties

\begin{tabular}{|l|c|}
\hline Compressive strength & $570 \mathrm{MPa}$ \\
\hline Yield strength & $98-290 \mathrm{MPa}$ \\
\hline Tensile strength ultimate & $160-450 \mathrm{MPa}$ \\
\hline Shear modulus & $69 \mathrm{GPa}$ \\
\hline Elastic modulus & $180 \mathrm{GPa}$ \\
\hline Poisson's ratio & 0.29 \\
\hline Elongation at break & $9.7 \%$ \\
\hline Hardness, Brinell & $160-300$ \\
\hline
\end{tabular}

Tab. 3 Titanium alloy Ti-6Al-4V properties

\begin{tabular}{|l|c|}
\hline Tensile strength & $1100 \mathrm{MPa}$ \\
\hline Yield strength & $880 \mathrm{MPa}$ \\
\hline Compressive yield strength & $970 \mathrm{MPa}$ \\
\hline Shear modulus & $44 \mathrm{GPa}$ \\
\hline Elastic modulus & $120 \mathrm{GPa}$ \\
\hline Poisson's ratio & 0.342 \\
\hline Elongation at break & $14 \%$ \\
\hline Reduction of area & $36 \%$ \\
\hline Hardness, Brinell & 334 \\
\hline
\end{tabular}
be:

Hence, the total force from Eq. (1) to be borne by the pair of lugs comes out to

$$
F=\frac{397.138[\mathrm{MPa}] \times \pi \times 9.6[\mathrm{~mm}] \times 9.6[\mathrm{~mm}]}{4}=28745.76 \mathrm{~N} .
$$

Thus force on one lug is $14372.88 \mathrm{~N}$. Nevertheless, the applied force in the simulation on lug is $16000 \mathrm{~N}$, just to ensure a factor of safety as large as possible.

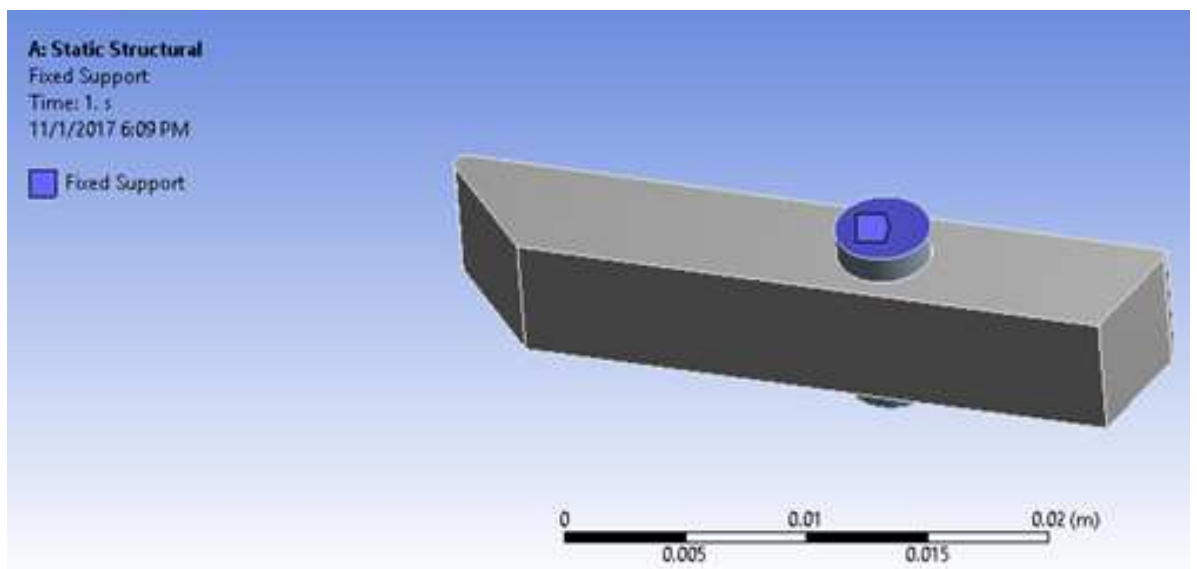

Fig. 7 Fixed supports at pin ends 


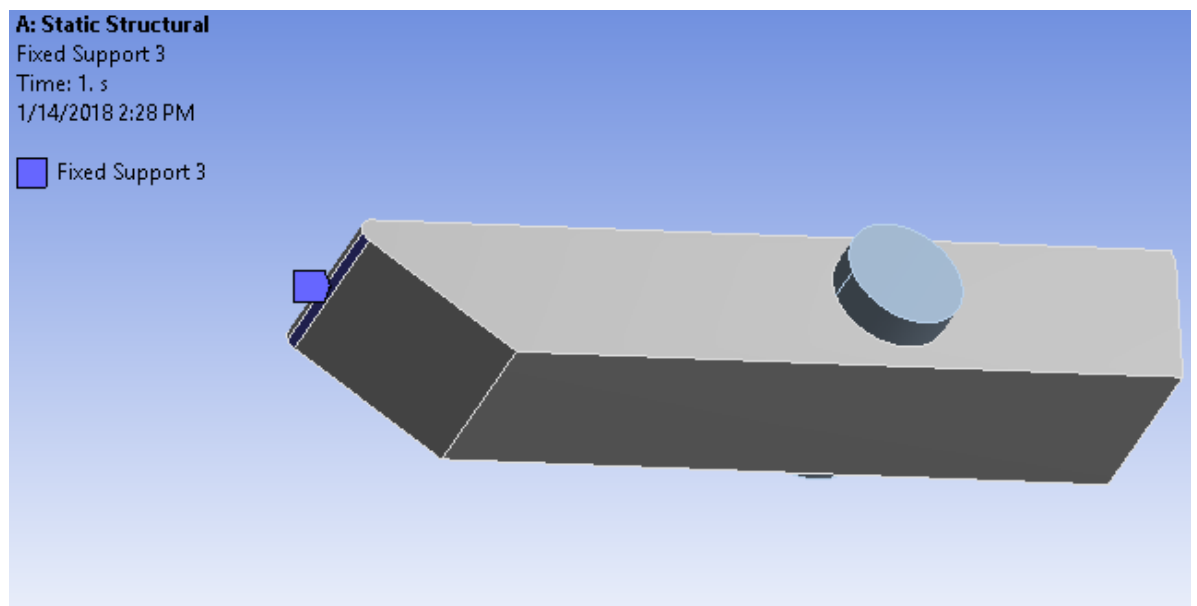

Fig. 8 Fixed support at rear end

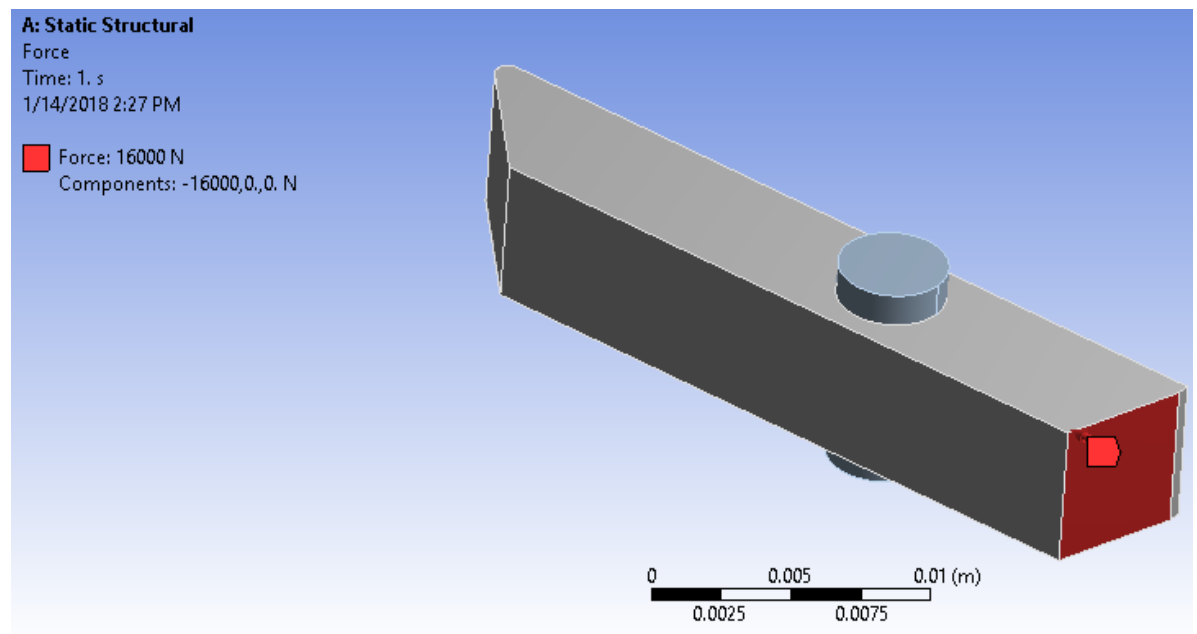

Fig. 9 Application of force

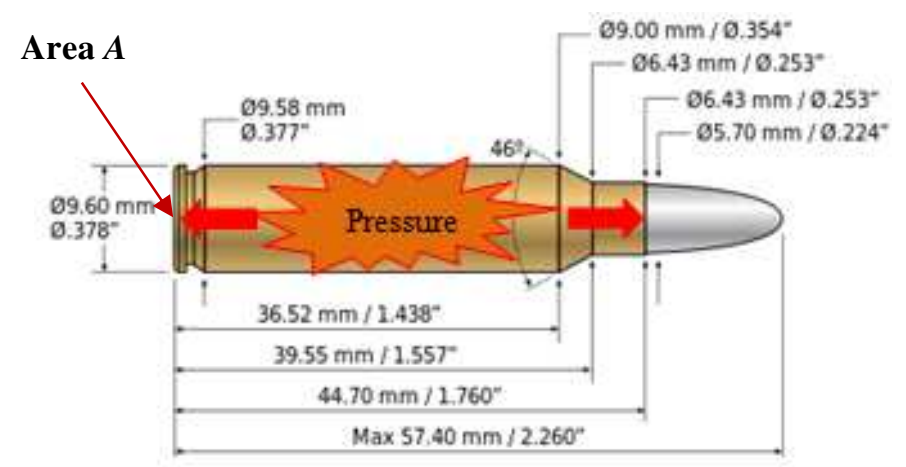

Fig. 10 Pressure acting upon cartridge body 


\section{Results}

1. Fig. 11 shows the simulated results of the analysis of safety factor for case 1 (material applied AISI 4340) in the form of coloured contours distributed over the bodies. The results prove that the chosen dimensions of the lugs were sufficient to bear the generated loads and allowing the mechanism to function without failure.

2. Fig. 12 shows the safety factor for grey cast iron as lug and pin material, under the imparted loads. It is clear that grey CI failed quite badly under the simulated loads.

3. Fig. 13 shows the distribution of contours showing factor of safety for case 3 (material being titanium alloy).

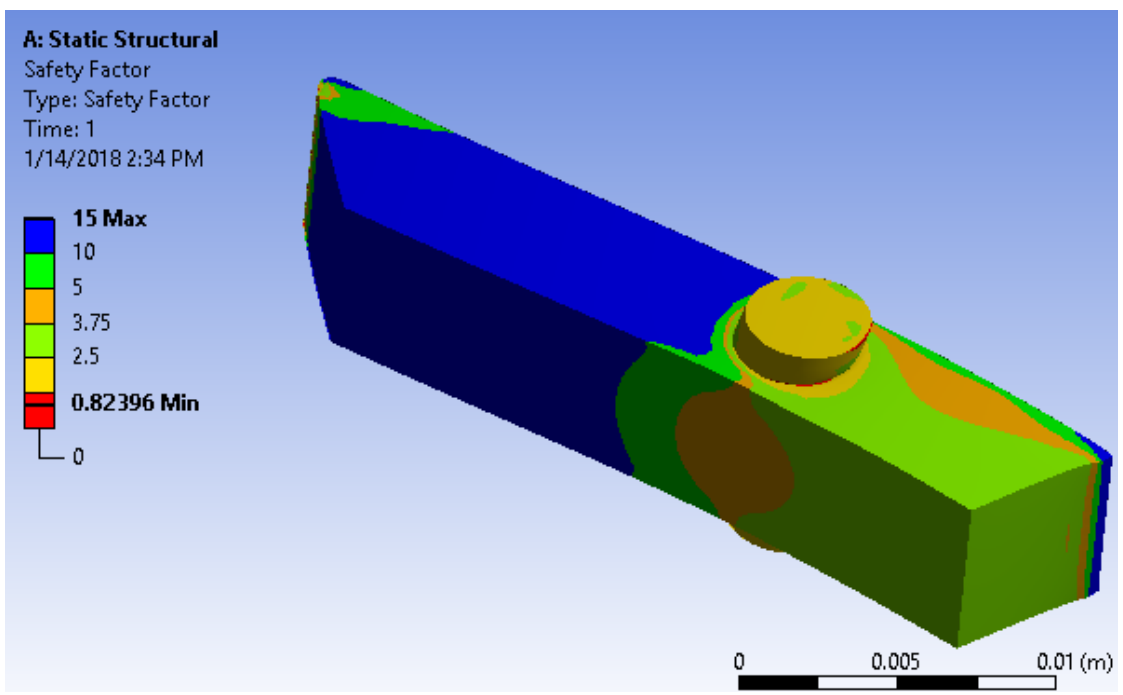

Fig. 11 Safety factor with AISI 4340

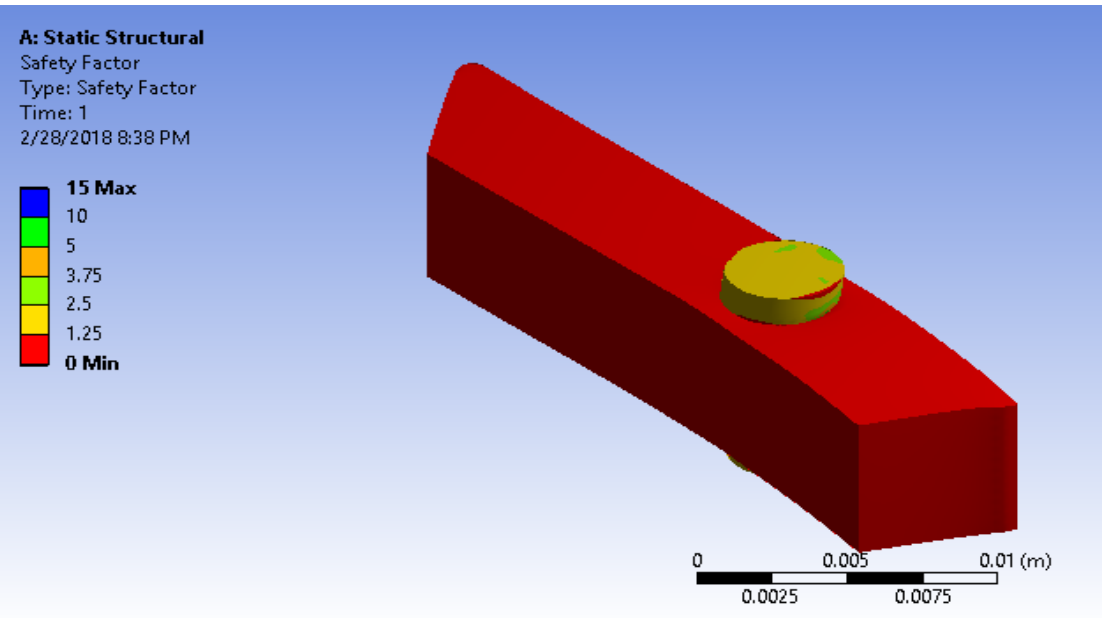

Fig. 12 Safety factor with grey cast iron 


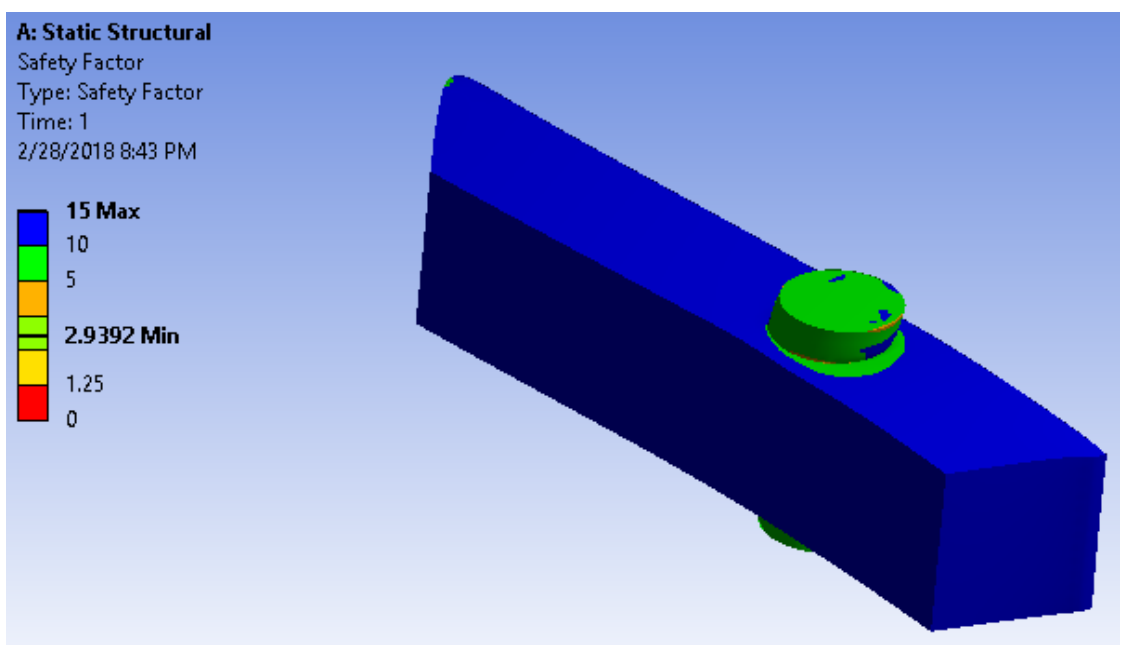

Fig. 13 Safety factor with titanium alloy

\section{Conclusions}

1. The results were in agreement with the required and expected outcomes.

2. ANSYS 14.5 version was used to generate the mathematical model and simulations.

3. Only an assembly of lug and a hinge pin were chosen as the critical parts under doubt to perform the analysis. The material applied was AISI 4340 in case 1 , grey cast iron in case 2, and titanium alloy Ti-6Al-4V in case 3.

4. Default meshing settings were applied with a change only in the size of mesh, which was reduced from coarse to fine.

5. The simulations proved that the chosen dimensions of the locking lugs were right for case 1 and 3, and hence all other dependent components designed considering these dimensions would function without discrepancy. Further, fatigue life for AISI 4340 can be improved by TiCN coatings [15] and shotpeening [16], while titanium alloy can be worked out with NiCrAlY [17] and tantalum coatings [18] to achieve the same.

6. It was clearly found that though being a brittle material, which was supposed to stand strong in compressive loading, grey cast iron failed quite miserably with almost nil factor of safety, apparently due to buckling loads.

7. In addition, it was found that titanium alloy Ti-6Al-4V offered a wider range of factor of safety (greater than 10), than AISI 4340. Hence, titanium alloy has to be the most favourable material for this application purpose.

8. Hence, the design of the most critical parts of the innovative mechanism was considered safe and could be expected to perform their function satisfactorily to make the bolt assembly and barrel assembly cycle independently.

9. Implementation and experimental validation of the designed mechanism is yet to be done in form of a complete product and the relevant manufacturing related aspects would become the base of other research works. 


\section{Acknowledgements}

This work was supported by the Department of Mechanical Engineering, Maulana Azad National Institute of Technology, Bhopal. The authors express their deep gratitude to the Department of Mechanical Engineering, MANIT for the benign support.

\section{References}

[1] EKSERGIAN R. Theory and Design of Recoil Systems and Gun Carriages. Ordnance Department document No. 2035. Washington, 1921.

[2] JOHNSON, J.R. and MELVIN, M. Firearm [US Patent]. US2094156A, 28. 9. 1937.

[3] BROWNING, J.M. Automatic Firearm [US Patent]. US1618510, 22. 2. 1927.

[4] Fedorov Avtomat [Wikipedia]. [cited 2018-01-10]. Available from: <https://en. wikipedia.org/wiki/Fedorov_Avtomat>.

[5] DOD: MIL-HDBK-5J, Department of Defense Handbook: Metallic Materials and Elements for Aerospace Vehicle Structures. 31. 1. 2003.

[6] PURDY, D.J. Modelling and Simulation of a Weapon Control System for a Main Battle Tank. In Proceedings of the eighth US Army Symposium on Gun Dynamics. Newport, 1996.

[7] NADEEM, A., BROWN, R.D. and HAMEED, A. Finite Element Modelling and Simulation of Gun Dynamics using "ANSYS”. In Proceedings of Tenth International Conference on Computer Modelling and Simulation. Cambridge, IEEE, 2008.

[8] THOMPSON, M.K. and THOMPSON, J.M. Chapter 1 Introduction to ANSYS and Finite Element Modelling. ANSYS Mechanical APDL for Finite Element Analysis. Butterworth-Heinemann, 2017. ISBN 9780128129814.

[9] OZMEN, D., KURT, M., EKICI, B. and KAYNAK, Y. Static, Dynamic and Fatigue Analysis of a Semi-automatic Gun Locking Block. Engineering failure analysis, 2009, vol. 16, no. 7. p. 2235-2244. ISSN 1350-6307. DOI 10.1016/ j.engfailanal.2009.03.014.

[10] SINGH, O. and SHARMA, S. Analysis and Comparison of Total Deformation of Welded Plates in Tensile and Fatigue Tests using ANSYS. Materials Today: Proceedings, 2017, vol. 4, no. 8, p. 8409-8417. DOI 10.1016/j.matpr.2017.07.185.

[11] ANSYS Workbench Strain Life Approach Lectures. [on line]. [cited 2018-01-09].

[12] AZO Materials [on line]. [cited 2018-01-10]. Available from: <https:// www.azom.com>.

[13] 5.56×45 mm NATO. [Wikipedia]. [cited 2018-01-10]. Available from: <https:// en.wikipedia.org/wiki/5.56\%C3\%9745mm_NATO>.

[14] DATER, P.H. and WONG, J.M. Effects of Barrel Length on Bore Pressure, Projectile Velocity and Sound Measurement. Seattle: Defense Technical Information Center, 2010.

[15] PUCHI-CABRERA, E.S. et al. Fatigue Properties of a SAE 4340 Steel Coated with TiCN by PAPVD. International Journal of Fatigue, 2007; vol. 29, no. 3, p. 471-480. DOI 10.1016/j.ijfatigue.2006.05.003. 
[16] TORRES, M.A.S. and VOORWALD, H.J.C. An Evaluation of Shot Peening, Residual Stress and Stress Relaxation on the Fatigue Life of AISI 4340 Steel. International Journal of Fatigue, 2002 vol. 24, no. 8, p. 877-886. DOI 10.1016/ S0142-1123(01)00205-5.

[17] PENG, X.M. et. al. Ablation Behavior of NiCrAlY Coating on Titanium Alloy Muzzle Brake. Surface and Coatings Technology, 2013, vol. 232, p. 690-694. DOI 10.1016/j.surfcoat.2013.06.078.

[18] HERTL, C., et al. Structural Characterisation of Oxygen Diffusion Hardened Alpha-tantalum PVD-coatings on Titanium. Materials Science and Engineering $C$, 2014, vol. 41, p. 28-35. DOI 10.1016/j.msec.2014.03.018. 